\title{
Seismic and Flood Risk Evaluation in Spain from Historical Data
}

\author{
Mercedes Ferrer ${ }^{1}$, Luis González de Vallejo², J. Carlos García ${ }^{1}$, \\ Angel Rodríguez ${ }^{3}$, and Hugo Estévez ${ }^{1}$ \\ ${ }^{1}$ Instituto Geológico y Minero de España, Ríos Rosas, 23. Madrid 28003 \\ m. ferreroime.es \\ ${ }^{2}$ Universidad Complutense de Madrid, Fac. CC. Geológicas, Ciudad Universitaria \\ Madrid 28040 \\ vallejøoge•. ucm .es \\ 3 Prospección y Geotecnia, S.A. Pedro Muguruza, 1, Madrid 28036 \\ Tel: +34913495776 \\ Fax: +34913495834
}

\begin{abstract}
Floods and earthquakes are two of the natural processes that cause in Spain economic and social losses, with major effects on the first ones. In order to evaluate the risk (social damages and economical losses) associated with these processes, the available historical data and information on happened events (from bibliographical and documentary sources, press, files, data bases, etc.) has been compiled and analysed exhaustively, including also the information related to the economic and social losses (damages, victims, direct and indirect economical losses, govemmental and insurance companies data, etc.). The analysis of the historical information has allowed to estimate the distribution and extent of the damages and losses due to floods and earthquakes in Spain, as well as the vulnerability of the national territory. The estimation of the damages and losses for the next three decades has been approached from the study of the flood and earthquake potential hazard in Spain, estimating the probabilities of occurrence of these processes with different magnitude/intensity for the period of reference. The present economic and social conditions of the territory have been considered, carrying out probabilistic estimations and valuing hypothetical situations of potential damage scenarios. The results allow to know the hazard (probability of occurrence of processes of certain magnitude) and risk degree (potential damages and losses) of every municipality of the country.
\end{abstract}

Keywerds: natural hazards, geological hazards, risk evaluation, floods, earthquakes, Spain.

\section{Introduction}

The geological and climatic characteristics of Spain originate natural hazards such as floods, landslides, earthquakes, etc. These processes give rise, in many cases, to important economical losses and social damages. However, these negative consequences are not inevitable and they must not be accepted like the price to pay by the use of the territory, land occupation or natural resources exploitation. The present damages and losses, and the associated reconstruction and reparation costs, can be reduced in an effective way. The geological hazards in Spain fre- 
quently affect populations and infrastuctures, and most of times damages are due to the occupation of hazardous areas and the lack of prevention measures and mitigation strategies. The prevention is the most effective way to avoid the social and economical damages. The preventive measures must be applied to the different scopes of the society, including the citizen information, the urban planning, and the design of safety infrastructures in hazard areas.

For the development and implementation of the different preventive measures it is necessary to have a complete and updated data base of the geological and hydrometeorological events and their incidence, what allows the analysis of the present losses and damages and the evaluation of the potential risks. This paper presents the study carried out for the evaluation of present (last 15 years) and future (next 30 years) risks due to floods and earthquakes in Spain, from the analysis of the geological and physical aspects and the economical, social and environmental factors which could be affected. Probabilistic estimations have been developed, as well as benefit-cost analysis and valuation of hypothetical situations of possible risk scenarios. The results of the study allow different practical applications, such us the definition of hazard and risk criteria for insurance companies, urban and land plarming, building and industrial installations specifications, infrastructures and life lines, prevention environmental risks, etc. Because of the national scale of the study, and the necessary degree of detail required, a specific methodology has been developed for the losses evaluation from the historical damages and losses compilation and inventory. It mainly consists in:

- Collection and compilation of historical data and information

- Data base preparation

- Analysis and evaluation of the present risk (based on last 15 years data) and the historical maximum risks in Spain due to floods and earthquakes.

- Potential risk evaluation for the next 30 years due to floods and earthquakes.

The work has been developed at a provincial and municipality level. The collected information has been introduce in a data base and treated with ARCVIEW. For the evaluation of the economical losses, both economical and social data have been used for the municipalities, updated at 2003. All the results have been represented in maps showing the distribution of the different hazard parameters and losses at municipality scale.

\section{Seismic Risk Evaluation in Spain from Historical Data}

\section{Seismicity Analysis}

The information related to earthquakes has been obtained from:

- Data bases and catalogues carried out by the Geological Survey of Spain (IGME, 1988a), including historical and recent data (from 565 to 1987).

- Seismic catalogues from the Geographical Institute of Spain for the national territory and north of Africa for the period 1987-2002. 
- Seismic catalogue of the simulation program SES 2002 (Civil Protection of Spain), including historical and recent earthquakes with intensity $\geq$ VI and/or magnitude $\geq 4.0$.

- Paper news related with earthquakes in Spain for the last 15 years.

The selected information has been classified and homogenized, including the data related to losses and damages in the affected areas, and the data have been in roduce in a database. 547 earthquakes have been collected, though 22.000 events were analysed with a minor intensity or magnitude than those causing damages. For each of the selected events the maximum distance to the epicenter has been calculate where the earthquake causes damages, getting concentric circles of "damage degree" corresponding to different intensities. For this, the different attenuation laws corresponding to the different regions of Spain were applied. The great scope of earthquakes generated in the Azores - Gibraltar zone stands out, in which the historical earthquakes that have taken place, though of big intensity, were felt in the opposite end of Spain, beside causing serious damages in cities of the south of Spain. These intensity or damage circles were represented for all the earthquakes in order to define areas with different seismicity degree. It was also prepare a map with the maximum intensity affecting each municipality for the period 1900-2002, when the historical data are better and homogeneous. With the information included in the data base and implemented in a GIS system (ARCVIEW), it was possible to cross the data corresponding to each earthquake for the period 1900-2002 and the different data corresponding to the municipalities, obtaining next information:

- Number of earthquakes and their intensity ( $\geq$ VI) affecting each of the municipalities.

- Classification of the municipalities according to their seismic activity in the last 102 years.

- A seismic hazard map of Spain at municipality scale based on the maximum registere intensity.

- Definition of the return period for different intensity earthquakes for each municipality.

A potential seismic hazard map for the next 30 years based on the historical and recent seismicity (last 102 years).

\section{Losses Evaluation}

In Spain there is not a complete information related to losses caused by historical earthquakes, including those of biggest intensity. Most of times, the data refer to general descriptions and, only in some few cases, the number of buildings affected, injured and killed people. It only exists detailed information of the economic losses cause by the Mula earthquake (Murcia, SW Spain, 1999). For this reason, for the losses evaluation it has been mainly considered the data corresponding to the Mula earthquake and some well documented recent big magnitude earthquakes in Italy with complete and detailed information about the provoked 
losses: Friuli (1976), Campania (1980) and Umbria (1997); (Trímboli, 2002). It has been considered that these earthquakes and their social and economical consequences present characteristics extrapolable to the Spanish territory. Apart form these case studies, for the evaluation of the potential losses it has been used the "Simulación de Escenarios Sísmicos SES-2002" program (developed by the Civil Protection of Spain and the Geøgraphical Institute of Spain), which has allowed the simulation of the main hist orical earthquakes eccurred in Spain (Table 1). This prøgram has been alsø used t• simmlate the effects of the italian earthquakes, demonstrating the representatives of the available data.

Table 1. Historical earthquakes in Spain and Italy for the evaluation of losses.

\begin{tabular}{|c|c|c|c|c|c|c|c|c|c|}
\hline Earthegake & $\begin{array}{c}\text { Mula } \\
1999 \\
\text { (1) }\end{array}$ & $\begin{array}{c}\text { Umbria } \\
1997 \\
\text { (2) }\end{array}$ & $\begin{array}{l}\text { Fruli } \\
1976 \\
(2)\end{array}$ & $\begin{array}{c}\text { Carmparia } \\
1990 \\
\text { (2) }\end{array}$ & $\begin{array}{c}\text { Arenas del } \\
\text { Pey } 1884 \\
\text { (3) }\end{array}$ & $\begin{array}{c}\text { Cehegin } \\
1948 \\
\text { (3) }\end{array}$ & $\begin{array}{c}\text { Queralps } \\
\text { T428 } \\
\text { (3) }\end{array}$ & $\begin{array}{c}\text { Adra } \\
1903 \\
(3)\end{array}$ & $\begin{array}{l}\text { Samia- } \\
\text { Becentea } \\
1985 \text { (3) }\end{array}$ \\
\hline Magnitude & 48 & 5,8 & 6.5 & 6.9 & 6.8 & 5 & 5,9 & 5 & 4.6 \\
\hline Intensity & VII & $1 x$ & $x$ & $x$ & $x$ & VIII & $1 x$ & VII & VI \\
\hline $\begin{array}{c}\text { Total } \\
\text { Lesses }\end{array}$ & 60,09 & 735,75 & $8,407,92$ & 50.095 .3 & 34.004 & 698,57 & $1,224,09$ & 550,22 & 9,45 \\
\hline $\begin{array}{l}\text { Population } \\
\text { aftloctod }\end{array}$ & 60.109 & 112.412 & 500.000 & 4641.520 & 2.674 .639 & 81.864 & 256.793 & 100.227 & 19.502 \\
\hline
\end{tabular}

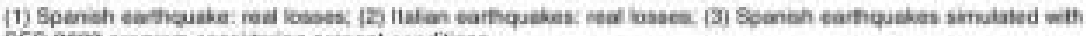
SES-2002 progam conaiduring preatnt condituse.

17 Milion eurse: $1^{-7}$ ) Population lving in the areas affected by intertsity $\geq \mathrm{VI}$.

The information related to the real losses has been studied in detail. For the evaluation of losses in the simulated earthquakes it has been considered:

The extension of the affected area, determined on the basis of the laws of attenuation of the intensity with the distance

The population affected in every municipality

- The types of buildings in the affected zones, classified depending on the type of construction and the use

- The vulnerability of the buildings

The vulnerability of the persons.

The information obtained about the damages caused by every earthquake has been:

Affected area $\left(\mathrm{km}^{2}\right)$

Number of inhabitants affected / Density of population

Total losses / Losses per $\mathrm{km}^{2}$ / Losses per Inhabitant

- Number of killed people / Number of injured people / Number of displaced persons

- Destroyed buildings / damaged buildings.

All the values of econ॰mic losses are up-t॰-date at 2003.

The previous information has allowed to study the degree of correlation among parameters as the intensity or the magnitude of the earthquakes with the losses, area and people affected, etc., and to define the corresponding mathematical ex- 
pressions that correlate the magnitude or intensity with the losses. Also to correlate the magnitude with the intensity expressions were used that allow to use both parameters indistinctly. The losses produced by earthquakes can be represented graphically and study their correlation and degree of adjustment with regard to equations of exponential and potential type. Figures 1 and 2 represent two examples of the functions of correlation: total population affected by earthquakes and total losses caused by earthquakes (Table 2).

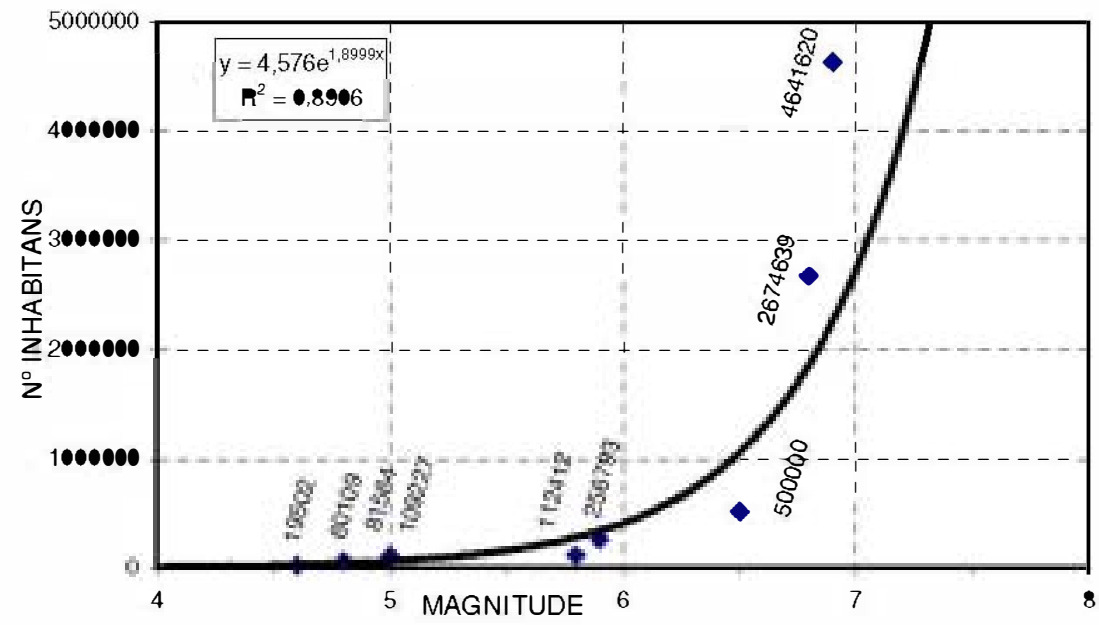

Fig. 1. Relation between population affected by earthquakes and magnitude.

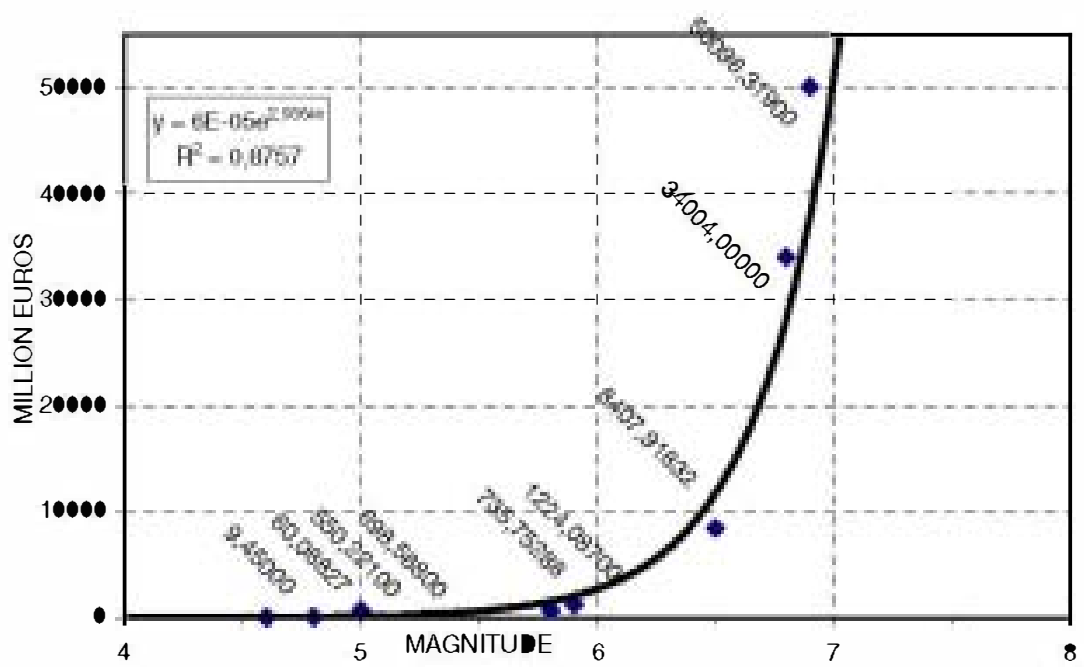

Fig. 2. Relation between total losses by earthquakes and magnitude. 
Table 2. Estimation of damages and losses by earthquakes.

\begin{tabular}{|c|c|c|}
\hline $\begin{array}{l}\text { Losses and } \\
\text { damages }\end{array}$ & Correlation with magnitude (M) & Correlation with intensify (I) \\
\hline $\begin{array}{c}\text { Affected } \\
\text { population } \\
\left(n^{\circ} \text { Inhabitants }\right)\end{array}$ & $n^{\circ} \operatorname{lnhab}=4,576 e^{1.6999 M}$ & $n^{\circ}$ Inhab $=4,576 \mathrm{e}^{1,8999\left(0.0351^{2}+2.9(n)\right.}$ \\
\hline $\begin{array}{l}\text { Total losses } \\
\text { TL }\left(€ \times 10^{6}\right)\end{array}$ & $\operatorname{TL}\left(€ \times 10^{8}\right)=6,038 \times 10^{-5} e^{2,9364 \mathrm{M}}$ & $T L=6,038 \times 10^{-5} e^{2,9364\left(0.0351^{2}+1.407\right)}$ \\
\hline
\end{tabular}

\section{Losses for the Period 1987-2002}

From the collected earthquakes occurred between 1987 and 2002 those with intensity $>\mathrm{V}$ or magnitude $>4$ were selected, that is, those causing notable damages. These earthquakes are 10: 2 with intensity VII, 1 with intensity VI-VII, 3 with intensity VI and 4 with intensity V - VI. This information emphasizes the low rate -f seismicity •bserved in Spain in the peried of study (1987-2002) in comparison with the registered in the last 102 years (1900-2002). Apart from this, 61 earthquakes have been selected with losses that have been an object of indemnification by the insurance companies. The calculation of the losses for the last 15 years (1987-2002) has been carried out by tw॰ different metheds:

- Correlation between the quantities (indemnifications) paid for the insurance companies and the total losses.

- Calculating the potential losses for every maximmm intensity felt in every municipality.

The quantities paid by the insurance companies represent around $2,24 \%$ of the total losses until the year 1996, and $20 \%$ from 1997 . The values obtained by both metheds are similar, emphasizing the representatively of both: $24 \times 10^{6}$ Euros and $210 \times 10^{6}$ Eures.

\section{Seismic Risk Evaluation for the Next 30 Years}

A total of 374 earthquakes have been studied of I $\geq V I$ and/or magnitude $\geq 4.0$ happened in Spain in the peried 1900-2001, most of them with intensity VI and VII. The analysis has allowed to know which are the municipalities affected by the earthquakes, the intensity felt for every earthquake and the number of times that a municipality has been affected by earthquakes of different intensity. Kn॰wing the seismicity affecting the national territory in the last 102 years, in absolute value, that is, total number of earthquakes of different intensity, as in a detailed way, number of earthquakes of different intensity for mmnicipality, it is possible to predict the seismicity that will concern t• Spain in the next 30 years. For this it is necessary to determine the probability of occurrence of the earthquakes of different intensity in the next 30 years, departing from a period of observation of 102 years. S•, there is obtained the number of earthquakes of different intensity predicted for the next 30 years. From these data there have been calculated the losses 
that they might cause using the expressions previously obtained of the study of the earthquakes in Spain and Italy and the program of simulation of seismic scenarios SES-2002 (Table 3).

Table 3. Number of potential earthquakes in Spain for the next 30 years (2003-2032).

\begin{tabular}{|c|c|}
\hline Intensity & $\begin{array}{c}\text { Number of } \\
\text { earthquakes }\end{array}$ \\
\hline VI & 70 \\
\hline VII & 19 \\
\hline VIII & 6 \\
\hline IX & 1 \\
\hline
\end{tabular}

As an example of the obtained results, Table 4 shows the total potential losses in Spain for the next 30 years by earthquakes of maximum intensity VII and VIII.

Table 4. Potential losses by earthquakes with intensity VII and VIII in Spain for the period $2003-2032$.

\begin{tabular}{|c|c|c|c|c|}
\hline \multirow{2}{*}{ Losses and damages } & \multicolumn{2}{|c|}{$\begin{array}{c}\text { Intensity VII } \\
\text { (19 earthquakes) }\end{array}$} & $\begin{array}{c}\text { Intensity Vill } \\
\text { (6 earthquakes) }\end{array}$ \\
\cline { 2 - 5 } & $\begin{array}{c}\text { Unit } \\
\text { Losses }\end{array}$ & $\begin{array}{c}\text { Total } \\
\text { Losses }\end{array}$ & $\begin{array}{c}\text { Unit } \\
\text { Losses }\end{array}$ & $\begin{array}{c}\text { Total } \\
\text { Losses }\end{array}$ \\
\hline Affocted area $\left(\mathrm{km}^{2}\right)$ & 766,92 & $14.571,5$ & $1.511,55$ & 9.070 \\
\hline Affected population $\left(\mathrm{n}^{\circ}\right.$ inhab.) & 29.797 & 566.143 & 80.790 & 484.740 \\
\hline \hline \multicolumn{5}{|c|}{} \\
\hline Losses $(\boldsymbol{\epsilon})$ / Inhabitant & 1.465 & 27.835 & 2.803 & 16.818 \\
\hline Destroyed buildings & 1 & 19 & 22 & 132 \\
\hline Damaged buildings & 3.225 & 61.275 & 9.018 & 54.108 \\
\hline
\end{tabular}

Unit losses: losses corresponding to one eatthquake

Total losses: Iosses for the total number of potential earthquakes ( 19 for $\mathrm{l}=\mathrm{VII}$ and 6 for $\mathbf{I}=\mathrm{VIII}$ )

In Table 5 appear the results of integrating the potential or predictable losses for the next 30 years for all the potential earthquakes (VI < Intensity = IX).

Table 5. Estimation of total losses for earthquakes in Spain for the period 2003-2032.

\begin{tabular}{|l|c|}
\hline \multicolumn{2}{|c|}{ Total losses } \\
\hline Affected area (km) & 56.719 \\
\hline $\begin{array}{l}\text { Affected population }\left(\mathrm{n}^{\circ}\right. \\
\text { jnhabitants) }\end{array}$ & 2.179 .802 \\
\hline Total losses $\left(\epsilon \times 10^{6}\right)$ & $4.366,122$ \\
\hline Destroyed buildings & 813 \\
\hline Damaged buildings & $\mathbf{2 3 6 . 9 1 4}$ \\
\hline
\end{tabular}

The losses have been calculated to regional, provincial and municipal level. Most -f the losses correspond to Andalusia, Murcia, Galicia and Valencia regiøns. 


\section{Flood Risk Evaluation in Spain from Historical Data}

\section{Historical Data Collection}

The information related to floods has been obtained from:

Available data bases and catalogues carried out by the Geological Survey of Spain (IGME, 1988a), including historical and recent data (from 420 to 1987).

- Data from Civil Protection of Spain.

- Documents and publications on floods happened in the different Spanish hydrographic basins.

Flood risk map of Spain (CEDEX, 1988).

- Governmental floods losses reports at provincial scale.

- Data from insurance companies.

- Press news related with floods in Spain for the last 15 years.

The selected information has been classified and homogenised, including the data related to losses and damages in areas affected by floods, and the data have been in roduce in a database, including date, duration, area affected, river, hydrographic basin, floo causes, flow, precipitation data, etc. 2534 floods causing damages have been collected, 217 corresponding to the period 1987-2002. The damages caused by floods have been classified:

- Infrastructures, including hydraulics, and public buildings

- Private properties: houses, vehicles, goods, etc. Industrial and commercial properties

Agriculture and cattle losses.

\section{Losses Evaluation for the Period 1987-2002}

Once collected the events occurred in the period 1987-2002, it was assigned to each of them the corresponding economic losses. In this way, 197 floods were selected for the period 1987-2002, with detailed descriptions of the events and the caused damages and losses. Neither the social damages nor the indirect economical losses were considered, because of the impossibility to obtain this information. By means of the correlation between the degree of damages declared (governmental reports) for every flood and the corresponding economical ata from the insurance companies, the floods have been classified with a different degree of damages. Figure 3 present the relation between the economic losses declared and the quantities paid by the insurance companies. Three definite well defined lines can be observed corresponding to:

- Urban floods

- Non urban floods

- Mixed type floods 


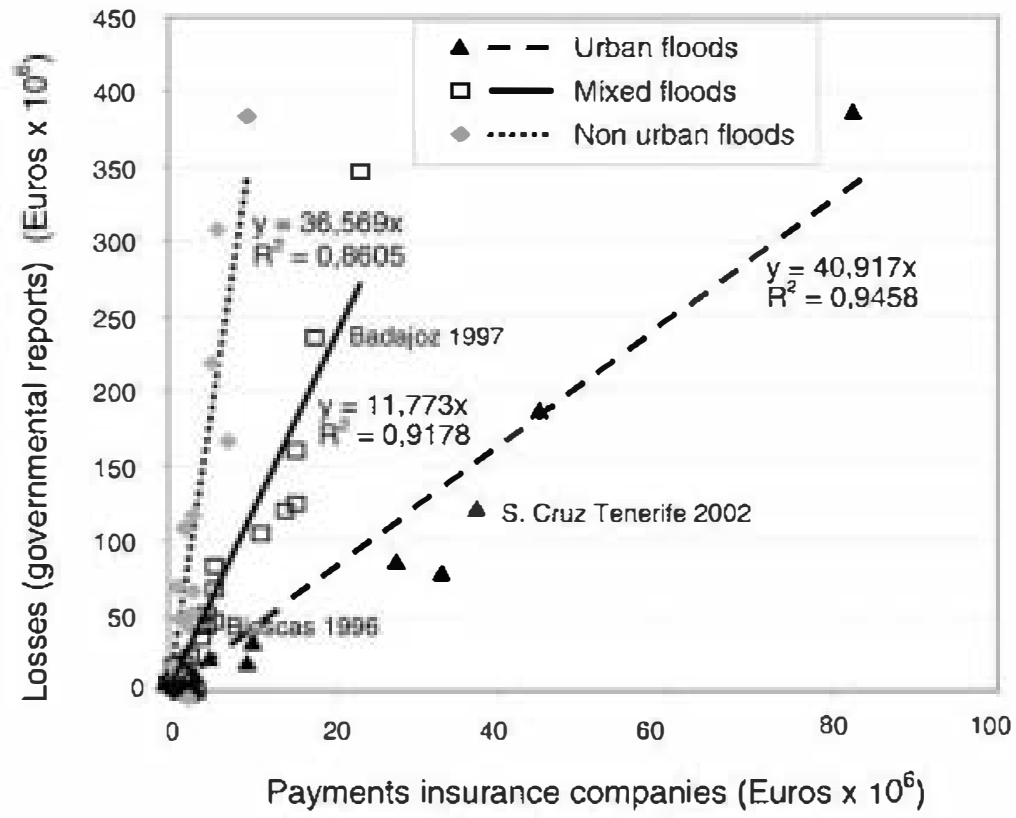

Fig. 3. Relation between the actual economic losses f floods and the quantities paid by the insur ance companies.

From these correlations, and depending on the type of flood, the losses have been estimated for those events not considered in governmental reports but paid for by the insurance companies. By this way, either by direct assignment (fr॰m the gøvernmental reports) or correlating with the insurance data, the economic losses corresponding to every flood between 1987 and 2002 have been obtained; the econ॰mic losses have got up-to-date t• 2003. They represent 12.000 Eurøs x $10^{\circ}$ for the complete national territory. The economical losses have been represented by provinces in a national map, and a complementary map has been prepared with the minicipalities affected by floeds in the peried 1987-2002.

\section{Flood Risk Estimation for the Next 30 Vears}

For the estimation of the losses that can cause the floeds in Spain in the next 30 years (2003-2032), there have been considered the floods occurred in the national territory from 1950, since for this period the available information about floods and the damages caused is complete. First, it has been carried out a classification of floods depending on the losses caused, that is, depending on the risk. 6 types of relative risk have been defined: 
Table 6. Classification of floods depending on the losses, both for event and province.

\begin{tabular}{|c|c|c|}
\hline $\begin{array}{c}\text { Risk } \\
\text { degree }\end{array}$ & $\begin{array}{c}\text { Losses per event } \\
\left(\text { Euros } \times 10^{6}\right)\end{array}$ & $\begin{array}{c}\text { Losses per province } \\
\left.\text { (Euros } \times 10^{\circ}\right)\end{array}$ \\
\hline I & $0-1$ & $0-0.5$ \\
\hline II & $1-5$ & $0.5-4$ \\
\hline III & $5-50$ & $4-30$ \\
\hline IV & $50-150$ & $30-70$ \\
\hline V & $150-300$ & $70-120$ \\
\hline VI & $>300$ & $>120$ \\
\hline
\end{tabular}

This degree of risk has been used to estimate potential losses at provincial level, from the number of floods of every risk degree per province for the period 1987 2002 and the corresponding losses. The number of flocels and the corresponding degree of relative risk for every province has been alsø evaluated for the period 1950-1987, from the available information on losses or from the qualitative descriptions of the damages. Als there has been calculated the number of fløeds of every degree of risk for year and province, for the peried 1950-2002, and the average value of economic losses that causes a flood of " $x$ " degree of risk in every province. The estimation of losses per province for the next 30 years has been carried out from the expression:

$$
\begin{gathered}
\mathrm{L}_{30}=30\left[\left(\mathrm{R}^{\mathrm{I}} \times \mathrm{L}^{\mathrm{I}}\right)+\left(\mathrm{R}^{\mathrm{II}} \times \mathrm{L}^{\mathrm{II}}\right)+\left(\mathrm{R}^{\mathrm{II}} \times \mathrm{L}^{\mathrm{II}}\right)+\left(\mathrm{R}^{\mathrm{IV}} \times \mathrm{L}^{\mathrm{IV}}\right)\right. \\
\left.+\left(\mathrm{R}^{\mathrm{V}} \times \mathrm{L}^{\mathrm{V}}\right)+\left(\mathrm{R}^{\mathrm{VI}} \times \mathrm{L}^{\mathrm{VI}}\right)\right]
\end{gathered}
$$

in which $\mathrm{L}_{30}=$ losses for the next 30 years; $\mathrm{R}^{\mathrm{x}}=$ Number of flocels per year of " $\mathrm{x}$ " risk degree estimated for the province. On determining the number of floeds per year of risk $x$ a conservative criterion has been followed; $L^{x}=$ Economic losses caused by a fleod of risk " $\mathrm{x}$ " in the province.

The estimated economic losses for floces for the peried 2003-2032 in the whole national territory ascend to $26.000 \times 10^{6}$ Eures, being the most affected regions those of Valencia, Andalusia and Catalonia. The losses estimated per province for next 30 years have been distributed by municipalities depending on the degree of risk estimated for each of them, as the product of the hazard (obtained from the number and intensity of the floeds eccurred in the municipality) and the vulnerability (considering the number of inhabitants and the index of economic level of each of them). The degrees of potential risk for municipalities are: - (nule or very low risk), 1 (low risk), 2 (mederate risk), 3 (high risk). Therefore, the losses estimated for every province (potential risk) distribute among the nmlnicipalities depending on the hazard degree and the vulnerability (population and econømic level). 


\section{Conclusions}

The study has allowed to have the following information and documentation:

- Valuations to national and municipal level of the impact of the geological risks in Spain and future losses predictions.

- Potential earthquakes and floods risk maps at national and municipal level.

- Data bases georeferenced, complete and updated at 2003 on the risks caused by earthquakes and floods in Spain.

- Detailed catalogues of the damages associated with these processes in the period 1900-2002, with homogeneous information updated to Euros of 2003

The estimations losses/intensity carried out for earthquakes have been validated and compared with real cases in Spain and Italy, which similar characteristics with Spain allow an acceptable correlation. An acceptable correlation has been defined between the intensity or magnitude of the earthquakes and the caused losses, depending on factors as the density of population or the economic level of the affected areas. The deduced mathematical expressions that relate these parameters allow to realize quantitative analyses that improve other empirical procedures used for evaluation of losses. The results of the study are of great usefulness for the insurance companies, for civil protection and for activities related to territorial plarming and land use.

\section{Acknowledgment}

This research project has been supported by the Geological Survey of Spain (IGME) and the Consorcio de Compensación de Seguros (CCS).

\section{References}

CEDEX (1988). Flood risk map of Spain. Scale 1/1.000.000.

Civil Protection of Spain - IGN (2002). "Simulación de Escenarios Sísmicos SES-2002" Program.

IGME (1988a). Catálogo Nacional de Riesgos Geológicos. 263 pp.

IGME (1988b). Impacto económico y social de los riesgos geológicos en España. 138 pp.

Trímboli, M. 2002. Reports on the Friuli (1976), Campania (1980) and Umbria (1997) earthquakes. Unpublished. 